\title{
Study of common carotid and brachial artery hemodynamic variations in periodontal disease in Central India-a clinical study
}

\author{
Grishmi Niswade $^{\mathrm{a}, *}$, Abhimanyu Niswade ${ }^{\mathrm{b}}$, Deepti Gattani ${ }^{\mathrm{a}}$, Girish Bhutada ${ }^{\mathrm{a}}$ \\ ${ }^{a}$ Department of Periodontology Swargiya Dadasaheb Kalmegh Smruti Dental College \& Hospital, Nagpur, India \\ ${ }^{\mathrm{b}}$ Government Medical College and Hospital, Nagpur, India
}

\section{A R T I C L E I N F O}

\section{Keywords:}

Common carotid artery

Brachial artery

Intimal thickness

Periodontitis

\begin{abstract}
A B S T R A C T
Background and aim: The linkage between periodontal and systemic diseases although well researched in the scientific area is not universally cognizant among the clinicians. It is critical to bring about the awareness of this inter-relationship as oral health is suggestive of systemic health. The aim of this study was a thorough hemodynamic assessment in patients having periodontal disease.

Settings and design: This is an observational cross sectional study. The patients were selected from Outpatient Department of Cardiology and Periodontology in a tertiary care hospital in urban setting in Nagpur, India.

Methods: The study was conducted on 45 patients aged between 35 and 65 years. Echo-Doppler examination for internal diameter (ID), intima-media thickness (IMT) and blood flow velocity (PSV) measurements was executed in the right and left common carotid artery (CCA) and brachial artery (BA). Periodontal disease status was determined using parameters like Gingival Index, Plaque Index, probing pocket depth (PPD) and clinical attachment level (CAL).

Statistical analysis: Due to multiple comparison groups one-way Analysis of variance (ANOVA) with Bonferroni multiple comparison tests have been performed to conduct all possible pair-wise comparisons of means.

Results: The present study showed that Carotid IMT and ID were high in the patients having cardiovascular disease (CVD) and periodontitis as compared to CVD alone, showing the additional effect caused by the presence of periodontal disease.

Conclusion: The study findings support the proposition that periodontal disease may be associated with endothelial dysfunction which leads to atherosclerosis or hardening of arteries indicating increased cardiovascular risk.
\end{abstract}

\section{Introduction}

Periodontitis is a chronic inflammatory state that has an effect on the supporting tissues of the teeth. ${ }^{1}$ The load of periodontal pathogens, antigens, endotoxins, and inflammatory cytokines of periodontal disease contribute in to the process of atherogenesis and thromboembolic events. Certain individuals may manifest increased levels of local and systemic inflammatory mediators which places them at an amplified risk for cardiovascular events. ${ }^{2}$

Case-control, cross-sectional, and longitudinal studies have established that periodontal disease is related with cardiovascular events, even after equalizing many confounding variables associated with both the conditions. ${ }^{3-6}$

Cardiovascular diseases (CVD) including coronary artery diseases
(CAD) like angina pectoris and myocardial infarction remains the primary cause of fatality in developed countries. CVDs are reported with very high frequency in India and accounts for the most common cause of deaths in the country. Heart disease has killed more than 1.7 million Indians in 2016 according to the 2016 Global burden of Disease Report. In the year 2000, there were an estimated 29.8 million individuals with CVD in India out of a total approximate population of 1.03 billion suggesting just about $3 \%$ overall prevalence. ${ }^{7}$

Low wall shear stress is time and again allied with increased diameters of arteries causing dilation. Enlarged arteries and raised blood pressure, and their combination, may increase circumferential wall tension of large arteries ${ }^{8}$ also called as parietal tension making individuals susceptible to development of heart disease. Arteriosclerosis or stiffened arteries have also been found to be associated with CVDs. ${ }^{9}$

\footnotetext{
* Corresponding author.

E-mail addresses: grish1989@gmail.com (G. Niswade), akniswade@gmail.com (A. Niswade), gattani.deepti@yahoo.com (D. Gattani), girish.bhutada@sdk-dentalcollege.edu.in (G. Bhutada).
} 
There is budding substantiation that research carried out in the peripheral circulation correlates with the coronary circulation and provides data which will be useful for forecasting the development of heart disease. For that reason the aim of this study was to substantiate the possible association between periodontal disease and atherosclerosis on the common carotid and the brachial artery.

\section{Material and methods}

This was an observational, cross sectional study in which a consecutive sample of 45 subjects aged between 35 and 65 years who came to the Outpatient Department of Cardiology Superspeciality Hospital, Nagpur, India during the period from December 2013 to November 2014 were selected which were then studied periodontally at the Department of Periodontology, Government Dental College, Nagpur, India. The subjects were then sent for Doppler examination. Sample size was estimated using a statistical software nMaster, Version 2.0 designed by BRTC, CMC. Vellore for IndiaCLEN. Sample size was determined considering correlation coefficient ( $r$ ) value as reported in the earlier study by Carallo et al., 2013. ${ }^{16}$ For revealing a significant, moderate correlation $(r=0.36)$ between Common Carotid Artery and Brachial artery with PI, a sample size of 44 was sufficient to attain $90 \%$ power with $90 \%$ confidence level. Hence a purposive, cross sectional sample of total 45 subjects was selected and was further equally divided in to 3 study groups (with $n=15$ per group). The study setting was urban and therefore a comparison between urban and rural setting was not made in the study.

The total sample of 45 patients was divided into 3 groups for comparison purpose. The 3 groups were made to identify the causative factor for hemodynamic alterations in common carotid and brachial artery hemodynamic alterations, whether it is CVD alone, periodontitis alone or a combination of both (periodontitis and CVD).

Group I: Subjects with CVD \& healthy periodontium $(\mathrm{n}=15)$

Group II: Subjects with CVD \& chronic periodontitis $(n=15)$

Group III: Subjects with chronic periodontitis \& without CVD $(\mathrm{n}=15)$

CVD in the study included coronary heart disease (CHD), arteriosclerosis, myocardial infarction and patients with cardiac arrest. The study consisted of subjects, male and female in the age group of 35-65 years; having chronic periodontitis with probing pocket depth (PPD) and clinical attachment loss (CAL) $\geq 4 \mathrm{~mm}$. Systemically healthy subjects were included in Group III of the study. Subjects were excluded if there was history of known systemic diseases (other than cardiovascular disease), antibiotic therapy or drug usage since last six months. Smokers and hypertensive patients were excluded in all the three groups. Pregnant \& lactating women, subjects taking Calcium channel blockers for treatment of cardiovascular disease, subjects who have undergone periodontal treatment within 6 months of study and Aggressive periodontitis patients were disqualified from the study.

All participants gave written informed consent and the Institutional Ethics Committee approved the study. The study protocol followed the Ethical Guidelines of the 2013 Declaration of Helsinki. Information concerning the past dental and medical history, drugs currently taken by the patient, gingival and periodontal status along with other routine clinical details was recorded in a specially designed case history format.

\section{Measurements}

\subsection{Ultrasound study}

Echo-Doppler assessment for arterial diameter (ID), thickness (IMT) and peak systolic velocity (PSV) measurements was carried out with an echo-color-Doppler Philips HD 11 XE (Royal Philips Electronics, the Netherlands).
For common carotid artery (CCD), parameters were assessed $1 \mathrm{~cm}$ proximally to left and right carotid bulb, obtaining two sets of measurements for each subject. For brachial artery (BA), the artery of both the arms was imaged approximately $10 \mathrm{~cm}$ over the elbow in the longitudinal section, on the front side of the biceps muscle, keeping the transducer perpendicular to the artery.

Internal diameter (ID) was measured as the intima-lumen interface between the near and the far wall of the artery. PSV was detected by placing the transducer in the centre of the vessel. The angle between the ultrasound beam and the longitudinal vessel axis was kept approximately $60^{\circ}$ which was standardized. Intima media thickness (IMT) was also measured and the findings were noted.

The measurements were carried out by priori trained and certified ultrasound observers. Periodontal and Echo- Doppler examinations were conducted by two different observers and none of the groups were acquainted with the results of other examination.

\subsection{Periodontal evaluation-}

Clinical and radiographic variables were used to assess the periodontal condition. Clinical evaluation was based on Gingival Index (GI) (Loe H and Silness P 1963), Plaque index (PI) (Silness and Loe 1964), probing pocket depth (PPD) at four sites per tooth and Clinical attachment loss (CAL) at four sites per tooth with a William's graduated periodontal probe. Radiographic alveolar bone level was observed using standard orthopantomograph (O.P.G.).

The Gingival Index proposed as a means for assessing the severity and extent of gingival inflammation in individual patients and Plaque index which is an indicator of the gingival plaque's load were used in the study.

\subsection{Statistical analysis}

Descriptive measures like Mean and Standard Deviation (Mean \pm SD) were calculated for all the parameters included in the study. Basic analysis focuses on estimation and comparison of parameters in all 3 groups. Due to multiple comparison groups one-way Analysis of variance (ANOVA) with Bonferroni multiple comparison tests have been performed to conduct all possible pair-wise comparisons of means. To assess correlation between various parameters with patient characteristics Pearson's correlation coefficient ( $r$ ) was used and its significance was tested with $t$-test.

Also multiple regression model was fitted to predict these parameters adjusting for patient's baseline characteristics, only those models with significant p-values are given in the results with corresponding regression coefficients (Beta) and adjusted R-square. Software used in the analysis was STATA, Version 10.1 (2010). P-value $<0.05$ is considered statistically considerable for all comparisons across the groups.

\section{Results}

Table 1 and Table 2 display the periodontal parameters of 45 subjects recruited in the study. PPD and CAL were significantly higher in

Table 1

Mean value of PPD and CAL.

\begin{tabular}{llllll}
\hline & & Group I & Group II & Group III & Total \\
\hline \multirow{2}{*}{ PPD } & No. of Subjects & 15 & 15 & 15 & 45 \\
& Mean PPD(mm) & 1.856 & 4.356 & 4.178 & 3.463 \\
& \pm SD & \pm 0.117 & \pm 0.379 & \pm 0.117 & \pm 1.175 \\
CAL & Mean CAL(mm) & 1.856 & 4.732 & 4.678 & 3.755 \\
SD & & \pm 0.117 & \pm 0.328 & \pm 0.138 & \pm 1.374 \\
\hline
\end{tabular}

Values are mean \pm standard deviation unless otherwise indicated. PPD, probing pocket depth; CAL, Clinical Attachment Level; SD, standard deviation; S, significant; NS, not significant. 
Table 2

Mean value of GI and PI.

\begin{tabular}{llllll}
\hline & Group I & Group II & Group III & Total \\
\hline Gingival Index & No. of subjects & 15 & 15 & 15 & 45 \\
& Mean GI & 0.733 & 1.210 & 1.248 & 1.064 \\
& \pm SD & \pm 0.457 & \pm 0.098 & \pm 0.098 & \pm 0.359 \\
Plaque Index & Mean PI & 0.810 & 1.293 & 1.316 & 1.14 \\
& \pm SD & \pm 0.421 & \pm 0.124 & \pm 0.129 & \pm 0.349
\end{tabular}

Values are mean \pm standard deviation unless otherwise indicated.GI, Gingival Index; PI, Plaque Index; SD, standard deviation; S, significant; NS, not significant.

Group II when compared to other groups whereas the GI and PI were significantly higher in Group III.

\subsection{Common carotid artery (CCA)}

Tables 3-5 display the hemodynamic variables of CCA and BA. When pair wise comparisons were made, the Mean value of PSV was highest in Group I $(90.26 \pm 24.879)$ which was not statistically significant when matched up to that of either Group II or III (Fig. 1). The Mean value of ID was highest in Group II $(0.74 \pm 0.094 \mathrm{~cm})$ which was statistically significant when compared to that of Group III but not significant when compared to that of Group I (Fig. 3). The Mean value of IMT was highest in Group II $(0.93 \pm 0.193 \mathrm{~cm})$ which was statistically significant when matched up to that of Group I and also significant when compared to Group III (Fig. 2).

\subsection{Brachial artery}

Tables 3-5 display the hemodynamic variables of CCA and BA. The Mean value of PSV was highest in Group III which was statistically significant when matched to that of Group II but not significant when compared to Group I (Fig. 4). The Mean value of ID was highest in Group II which was not statistically significant when matched up to that of Group I or Group III (Fig. 6). The Mean value of IMT was highest in Group II which was statistically significant when compared to that of Group III but not significant when compared to Group I (Fig. 5).

\subsection{Correlation between ultrasound parameters and subject characteristics}

Table 6 depicts that there is significant role of Sex and PPD in predicting Right Brachial artery diameter in all the study subjects ( $n=45$ ) taking into account the role of other subject characteristics, that is gender and PPD are more commonly related to the diameter of BA. In this analysis, Right CCA ID was statistically significant when correlated with sex of the study subject. Also, the Left CCA IMT was statistically significant when correlated with pocket depth. Right BA PSV was significantly correlated with the age of the patient.

\section{Discussion}

The present study included 45 subjects with Mean age of $46.4 \pm 8.2$ years and $55.56 \%$ of them were males and $44.44 \%$ of females. When the study groups were compared with each other with regards to age and sex, the results were not statistically significant which may be due to random selection of patients. However, it has been suggested that loss of teeth and persistent periodontitis linked to subclinical atherosclerosis is more in males as compared to females. ${ }^{10}$ American Heart Association in 2015 on National health and Nutritional survey states that prevalence of CHD by age and sex is equal in the age group of 20-39 years of age and prevalence increases in men in the age group of 40-59 years, 60-79 years and above 80 years of age.

In this study, it was found that all the periodontal parameters were considerably correlated with the presence of CVD. Our results were in agreement with the study by Humphrey et al., 2008 who observed that periodontal disease makes the individual susceptible for CVD including CHD that is autonomous of long-established CHD risk factors. ${ }^{11} \mathrm{Ba}-$ hekar et al., 2007 conducted a meta-analysis to assess the association between periodontitis and CHD. Meta-analysis of the 5 prospective cohort studies (86092 patients) shows that those with periodontitis had a 1.14 times greater risk of developing CHD than the controls. This meta-analysis indicated that predominance of CHD was significantly amplified in periodontal disease. Therefore, periodontal disease may increase the possibility for developing CHD. ${ }^{12}$

There is a growing belief that hemodynamic alterations in CCA can be perceived as suggestive of generalized atherosclerosis. Carotid and Brachial artery B-mode ultrasonography provides assessment of lumen diameter, IMT and incidence and amount of plaques. Another method to assess endothelial function is flow mediated dilation. It is a widely used test, but the interpretation of results is not consistent and it is an invasive technique. Hence in our study we used the non-invasive Bmode ultrasonography with Echo Doppler. We have tried to eliminate the error by performing ultrasound on both left and right CCA and BA.

The present study showed that the IMT of Right and Left CCA was highest in Group II as matched up to other groups, which was statistically significant. The Mean value of IMT in Group II was $0.957 \pm 0.254 \mathrm{~mm}$ in Right CCA and $0.92 \pm 0.132 \mathrm{~mm}$ in Left CCA. Prati et al., 2008 reported that an IMT of greater than $0.9-1 \mathrm{~mm}$ is likely to be suggestive of atherosclerosis and greater risk of cardiovascular disease. ${ }^{13}$ Comparable findings were accounted by Beck et al., 2001 who stated on the relationship of periodontitis with carotid artery IMT and established that those with severe periodontal disease had 1.3 times the probabilities of having thick carotid artery walls $(\geq 1 \mathrm{~mm})$ contrasted with individuals with less severe disease, after correction of long-established risk factors for atherosclerosis. ${ }^{14}$

This study showed that ID of Right and Left CCA was higher in Group II as compared to the other groups. The ID was highest in Group II which was statistically considerable when matched up to that of Group III. These results are in agreement with the study carried out by Soder et al., 2005 who conducted a study to assess the association of periodontal disease in the development of early atherosclerotic lesions.

Table 3

Mean value of PSV of Right and Left CCA and BA.

\begin{tabular}{|c|c|c|c|c|c|c|c|c|c|}
\hline & & \multicolumn{2}{|l|}{ Group I } & \multicolumn{2}{|l|}{ Group II } & \multicolumn{2}{|l|}{ Group III } & \multicolumn{2}{|l|}{ Total } \\
\hline & & Rt & Lt & Rt & Lt & Rt & Lt & Rt & Lt \\
\hline \multirow[t]{2}{*}{ Common carotid Artery } & No of subjects & 15 & & 15 & & 15 & & 45 & \\
\hline & $\begin{array}{l}\text { Mean PSV }(\mathrm{cm} / \mathrm{sec}) \\
\pm \mathrm{SD}\end{array}$ & $\begin{array}{l}87.2 \\
\pm 26.6\end{array}$ & $\begin{array}{l}93.3 \\
\pm 23.1\end{array}$ & $\begin{array}{l}71.9 \\
\pm 12.8\end{array}$ & $\begin{array}{l}79.6 \\
\pm 18.9\end{array}$ & $\begin{array}{l}85.9 \\
\pm 28.1\end{array}$ & $\begin{array}{l}86.7 \\
\pm 20.3\end{array}$ & $\begin{array}{l}81.6 \\
\pm 24.1\end{array}$ & $\begin{array}{l}86.5 \\
\pm 21.1\end{array}$ \\
\hline Brachial Artery & $\begin{array}{l}\text { Mean PSV }(\mathrm{cm} / \mathrm{sec}) \\
\pm \mathrm{SD}\end{array}$ & $\begin{array}{l}73.3 \\
\pm 14.2\end{array}$ & $\begin{array}{l}70.9 \\
\pm 14.4\end{array}$ & $\begin{array}{l}64.1 \\
\pm 10.3\end{array}$ & $\begin{array}{l}68.1 \\
\pm 13.7\end{array}$ & $\begin{array}{l}82.8 \\
\pm 20.4\end{array}$ & $\begin{array}{l}87.7 \\
\pm 23.9\end{array}$ & $\begin{array}{l}73.3 \\
\pm 17.1\end{array}$ & $\begin{array}{l}75.5 \\
\pm 19.6\end{array}$ \\
\hline
\end{tabular}

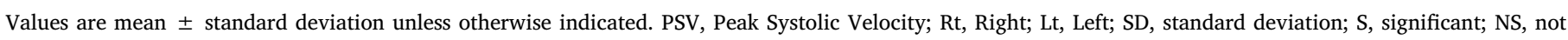
significant. 
Table 4

Mean value of ID of Right and Left CCA and BA.

\begin{tabular}{|c|c|c|c|c|c|c|c|c|c|}
\hline & & \multicolumn{2}{|l|}{ Group I } & \multicolumn{2}{|l|}{ Group II } & \multicolumn{2}{|l|}{ Group III } & \multicolumn{2}{|l|}{ Total } \\
\hline & & Rt & $\mathrm{Lt}$ & Rt & Lt & Rt & Lt & Rt & Lt \\
\hline Common carotid & No of subjects & 15 & & 15 & & 15 & & 45 & \\
\hline Artery & $\begin{array}{l}\text { Mean ID }(\mathrm{cm}) \\
\pm \mathrm{SD}\end{array}$ & $\begin{array}{l}0.68 \\
\pm 0.1\end{array}$ & $\begin{array}{l}0.69 \\
\pm 0.1\end{array}$ & $\begin{array}{l}0.75 \\
\pm 0.1\end{array}$ & $\begin{array}{l}0.72 \\
\pm 0.07\end{array}$ & $\begin{array}{l}0.6 \\
\pm 0.09\end{array}$ & $\begin{array}{l}0.57 \\
\pm 0.09\end{array}$ & $\begin{array}{l}0.67 \\
\pm 0.12\end{array}$ & $\begin{array}{l}0.66 \\
\pm 0.11\end{array}$ \\
\hline Brachial Artery & $\begin{array}{l}\text { Mean ID }(\mathrm{cm}) \\
\pm \mathrm{SD}\end{array}$ & $\begin{array}{l}0.38 \\
\pm 0.08\end{array}$ & $\begin{array}{l}0.38 \\
\pm 0.08\end{array}$ & $\begin{array}{l}0.41 \\
\pm 0.05\end{array}$ & $\begin{array}{l}0.40 \\
\pm 0.06\end{array}$ & $\begin{array}{l}0.37 \\
\pm 0.04\end{array}$ & $\begin{array}{l}0.35 \\
\pm 0.05\end{array}$ & $\begin{array}{l}0.39 \\
\pm 0.06\end{array}$ & $\begin{array}{l}0.38 \\
\pm 0.07\end{array}$ \\
\hline
\end{tabular}

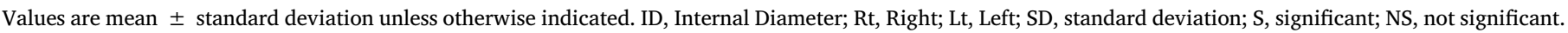

Table 5

Mean value of IMT of Right and Left CCA and BA.

\begin{tabular}{|c|c|c|c|c|c|c|c|c|c|}
\hline & & \multicolumn{2}{|l|}{ Group I } & \multicolumn{2}{|l|}{ Group II } & \multicolumn{2}{|l|}{ Group III } & \multicolumn{2}{|l|}{ Total } \\
\hline & & Rt & Lt & Rt & Lt & Rt & $\mathrm{Lt}$ & Rt & Lt \\
\hline Common carotid & No of subjects & 15 & & 15 & & 15 & & 45 & \\
\hline Artery & $\begin{array}{l}\text { Mean IMT(cm) } \\
\pm \mathrm{SD}\end{array}$ & $\begin{array}{l}0.62 \\
\pm 0.23\end{array}$ & $\begin{array}{l}0.61 \\
\pm 0.25\end{array}$ & $\begin{array}{l}0.95 \\
\pm 0.25\end{array}$ & $\begin{array}{l}0.92 \\
\pm 0.13\end{array}$ & $\begin{array}{l}0.52 \\
\pm 0.14\end{array}$ & $\begin{array}{l}0.58 \\
\pm 0.2\end{array}$ & $\begin{array}{l}0.70 \\
\pm 0.28\end{array}$ & $\begin{array}{l}0.70 \\
\pm 0.25\end{array}$ \\
\hline Brachial Artery & $\begin{array}{l}\text { Mean IMT(cm) } \\
\pm \mathrm{SD}\end{array}$ & $\begin{array}{l}0.44 \\
\pm 0.11\end{array}$ & $\begin{array}{l}0.42 \\
\pm 0.10\end{array}$ & $\begin{array}{l}0.54 \\
\pm 0.13\end{array}$ & $\begin{array}{l}0.53 \\
\pm 0.08\end{array}$ & $\begin{array}{l}0.31 \\
\pm 0.11\end{array}$ & $\begin{array}{l}0.34 \\
\pm 0.11\end{array}$ & $\begin{array}{l}0.43 \\
\pm 0.15\end{array}$ & $\begin{array}{l}0.43 \\
\pm 0.13\end{array}$ \\
\hline
\end{tabular}

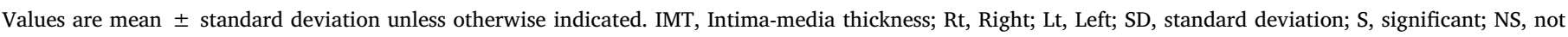
significant.

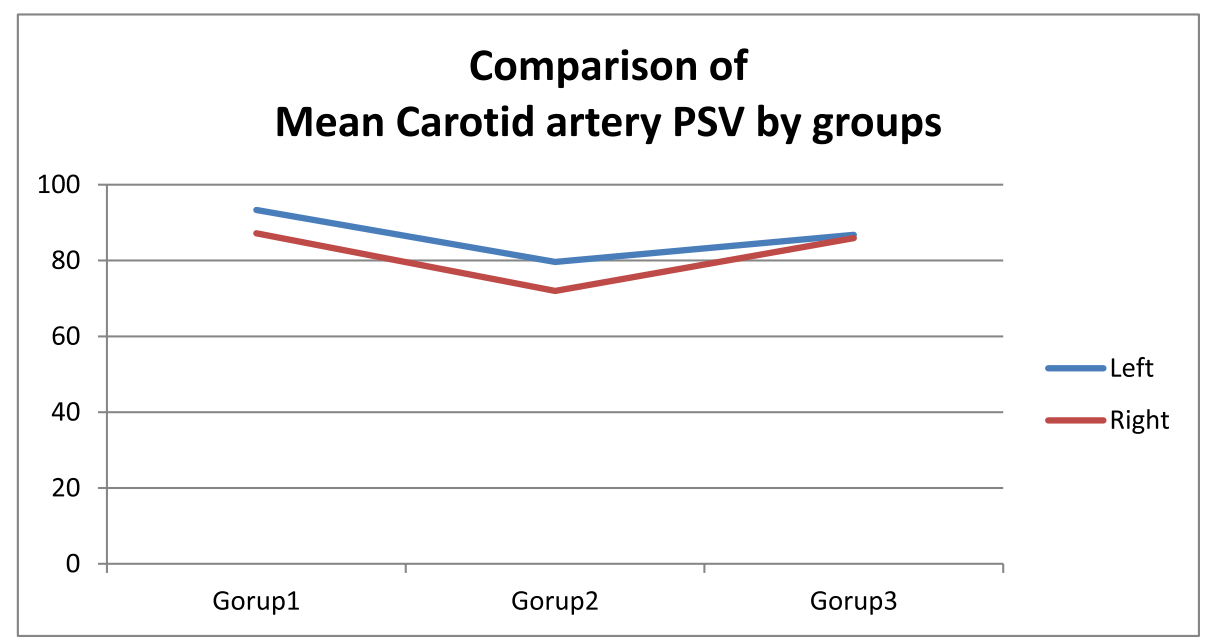

Fig. 1. Comparision of mean carotid artery PSV by groups.

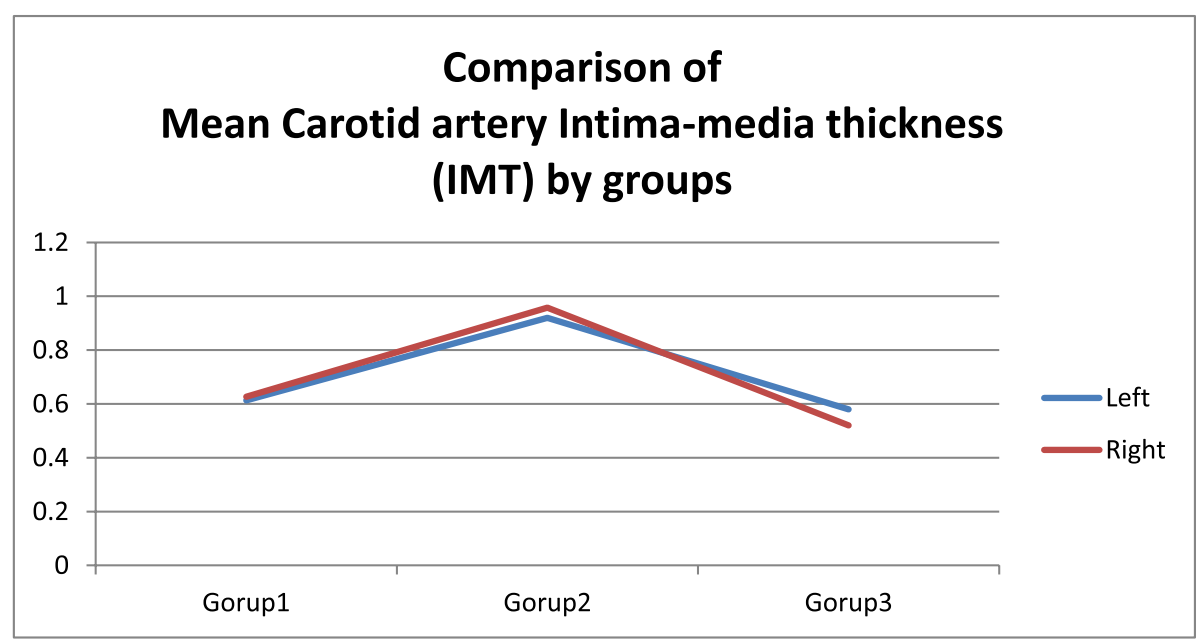

Fig. 2. Comparision of mean carotid artery intima-media thickness (IMT) by groups. 


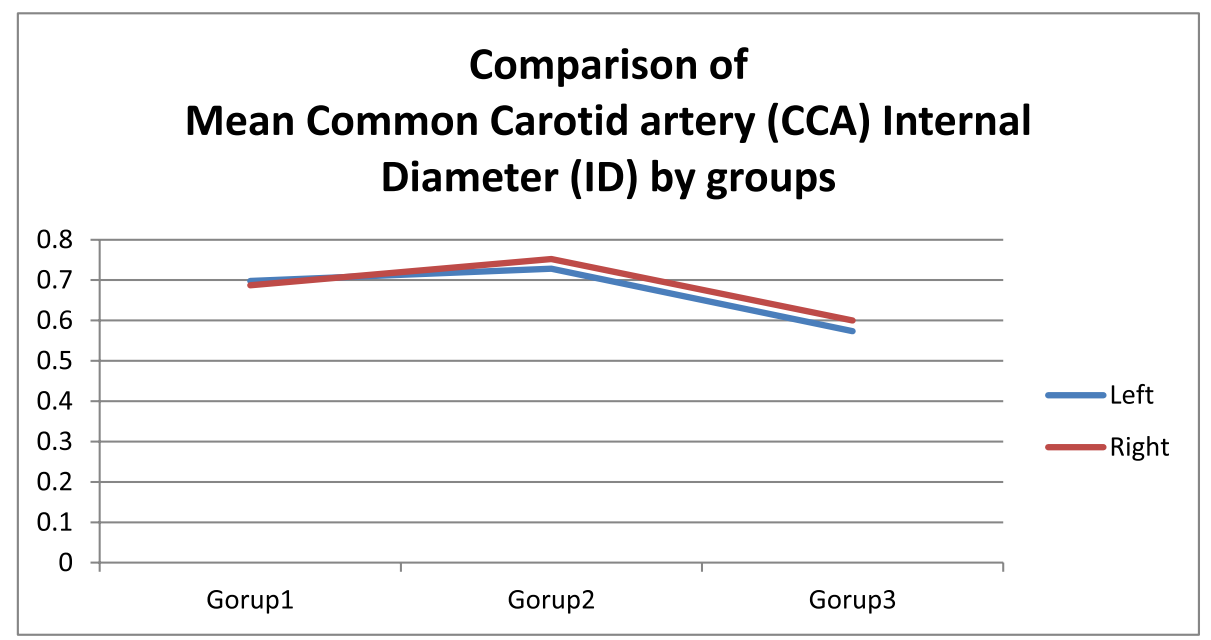

Fig. 3. Comparision of mean common carotid artery (CCA) Internal diameter (ID) by groups.

The results indicate that the mean values of IMT and ID were significantly greater in patients with periodontal disease than controls (periodontally healthy group) suggesting that periodontitis is linked with development of early atherosclerotic lesions. ${ }^{15}$ The PSV, however, of Right and Left CCA, was lowest in Group II except was not statistically significant. These results might be due to patient population of our study which may be in an early atherosclerotic stage.

Carallo et al., 2013 performed a study to authenticate the likely liaison between periodontal diseases and shear and tensile forces on CCA and BA. Carotid and brachial parietal tensions were notably related with periodontal indices; especially PPD. Shear stress gave similar results indicating significant association with periodontal parameters. They concluded that periodontal disease is linked to an intricate atherosclerotic prone hemodynamic imbalance, particularly in large elastic arteries. ${ }^{16}$ Also, in the present study, similar results were obtained.

The PSV of right and left BA was lowest in Group II which was statistically considerable when matched up to Group III. The IMT was highest in Group II which is also statistically significant when compared to Group III. The ID was also highest in Group II but is not statistically significant when compared to other groups. Amar et al., 2003 conducted a study to conclude whether periodontal disease is related with a systemic pathologic state of the endothelium of brachial artery. They evaluated flow mediated dilatation and nitro-glycerine mediated dilation of the brachial artery with a non invasive ultrasound method or duplex study in 26 subjects with severe periodontal disease and 29 control subject. Subjects with severe periodontal disease had lesser flow-mediated dilation compared with control patients. The study suggested that individuals with severe periodontal disease display endothelial dysfunction and signs of systemic inflammation thus increasing the risk of developing cardiovascular disease. ${ }^{17}$ Analogous results were also reported by BireHoltfreter et al., 2013. ${ }^{18}$

When the Right and Left CCA characteristics such as PSV, IMT and ID were compared with the study subject's characteristics such as age, sex, PPD, CAL, GI and PI, it was found that only Right CCA ID was statistically significant when correlated with sex of the study subject as shown in Table 6. Jaroslaw Krejza et al., 2006 demonstrated that carotid arteries are undersized in females after correction of body, neck size, age and blood pressure. They concluded that women are at a greater cardiovascular risk. ${ }^{19}$ Similar results were reported in our study that gender plays a significant role in predicting the Right CCA ID.

Also, in the present study, the Left CCA Intima- Media Thickness (IMT) was statistically significant when correlated with PPD. Comparable results were also reported by Hayashida et al., 2013. ${ }^{20}$

In this study, when the Right and Left BA characteristics were compared it was found that Right BA PSV was significantly correlated with the age of the patient. Parallel findings were accounted by Credeur et al., 2009 who proposed that brachial PSV increases with age which is

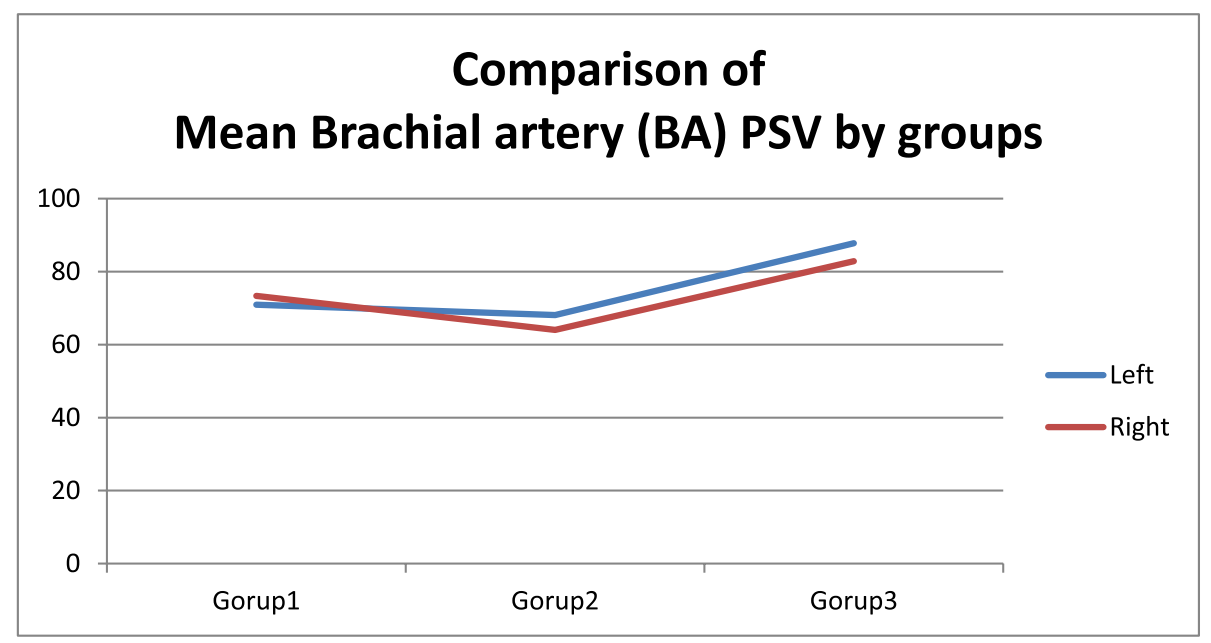

Fig. 4. Comparision of mean brachial artery (BA) PSV by groups. 


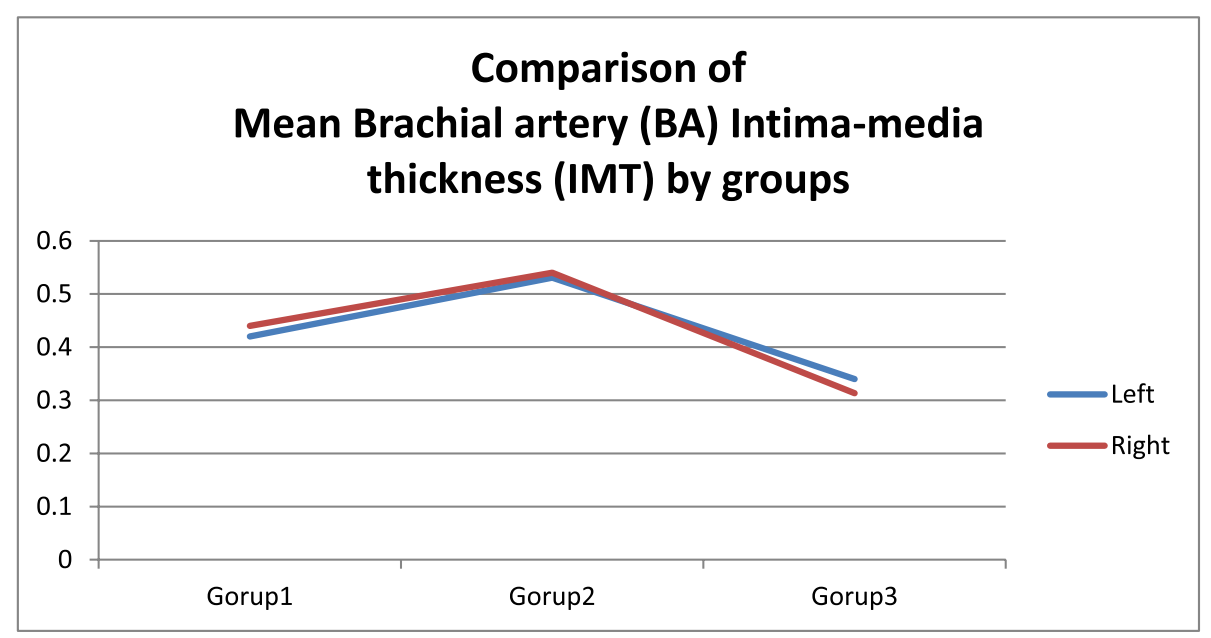

Fig. 5. Comparision of mean brachial artery (BA) intima-media thickness (IMT) by groups.

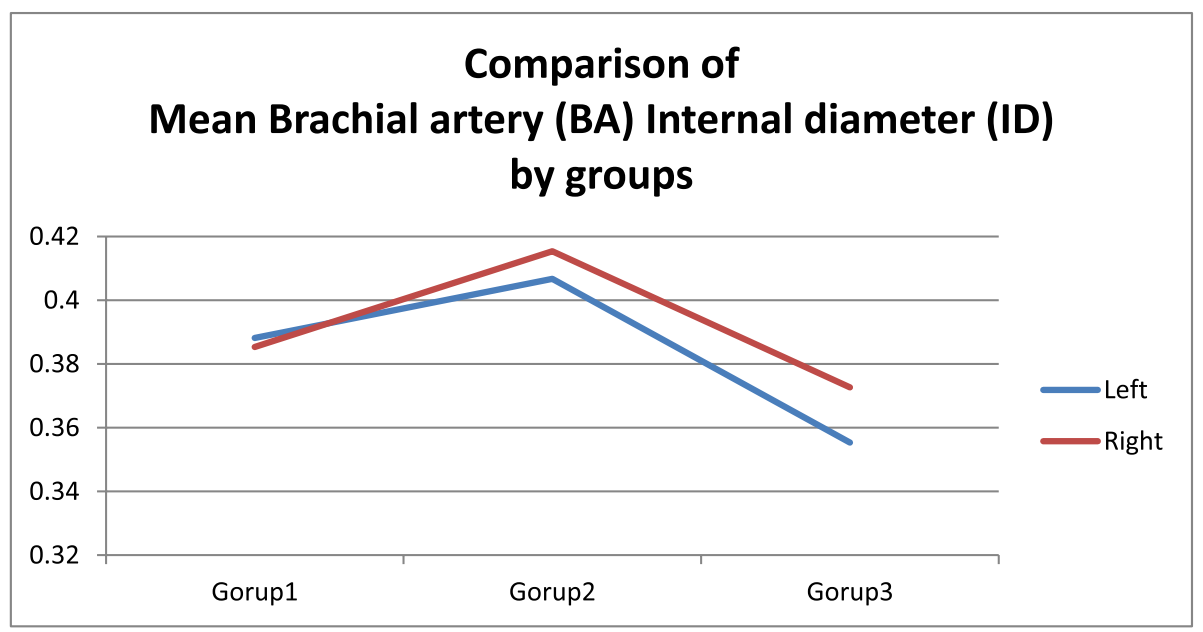

Fig. 6. Comparision of mean brachial artery (BA) internal diameter (ID) by groups.

Table 6

Multiple regression analysis.

\begin{tabular}{|c|c|c|c|c|c|c|c|}
\hline \multirow[t]{2}{*}{ Variables } & Right CCA & Left CCA & Left CCA & Right BA & Right BA & Left BA & Left BA \\
\hline & IMT & IMT & ID & IMT & ID & IMT & ID \\
\hline Age (years) & & & $0.003,0.06$ & & & & \\
\hline Sex 0.002 & & & $-0.29,0.05$ & $-0.30,0.04$ & $-0.42,0.003$ & $-0.31,0.03$ & -0.43 \\
\hline PPD(units) & $0.78,0.007$ & $0.65,0.01$ & $0.23,0.03$ & & $0.13,0.04$ & & \\
\hline CAL(units) & $-0.57,0.02$ & $-0.48,0.03$ & -0.210 .04 & & & & \\
\hline
\end{tabular}

$(\beta, \mathrm{p}$ value are provided).

related to a decline in physical function. ${ }^{21}$ Right BA IMT and ID, the Left BA IMT and ID were also significantly correlated with the sex of the study subject. Similar results were found by Van der Heijden et al., 2000 wherein the author suggested that brachial artery ID and compliance increases with age and is more distinct in females than in males. ${ }^{22}$

When multiple linear regression analysis was performed to predict Right BA ID in study subjects adjusting for their characteristics, it was observed that there is significant role of Sex and PPD in predicting Right BA diameter in all the study subjects taking into account the role of other subject characteristics such as age, CAL, GI and PI. Also there is significant role in of PPD and CAL in predicting Right CCA IMT, Left CCA IMT and that of age, PPD and CAL in predicting Left CCA ID. Similar results are reported by Beck et al., 2001 suggesting that the severity of clinical attachment loss plays a role in cardiovascular events. ${ }^{23}$ Also, results in the same line were verified in a study by Carallo et al., 2013.

\section{Limitations}

This study has some confines. The data from such observational studies does not advocate that periodontal disease is a causative factor 
for development of CVD because cross sectional studies do not conclude whether periodontitis occurred before the onset of CVD or not. Also, the alliance between periodontal disease and endothelial dysfunction may reveal residual confounding factors by known or yet unknown CVD risk factors in spite of our attempt to counterpart the groups with regression analysis. The extent and thickness of plaque was not examined in the present study as it is better indicator of late atherosclerotic lesions, whereas endothelial dysfunction is a marker of early atherosclerosis. A randomized controlled trial (RCT) showing improved endothelial function after periodontal therapy would provide better confirmation of the linkage between periodontal disease and CVD.

\section{Conclusion}

It was concluded that periodontitis is associated with early carotid and brachial atherosclerosis, as seen from the significant results in the present study; thus supporting the assumption that periodontal disease may be associated with endothelial dysfunction which leads to atherosclerosis or hardening of arteries indicating increased cardiovascular risk.

\section{Conflicts of interest}

The authors do not have conflict of interests in relation to this study.

\section{Financial Support}

No funding was available for this study.

\section{Appendix A. Supplementary data}

Supplementary data to this article can be found online at https:// doi.org/10.1016/j.cegh.2019.03.005.

\section{References}

1. Offenbacher S. Periodontal diseases: pathogenesis. Ann Periodontol. 1996;1:821-878.

2. Beck J, Offenbacher S, et al. Periodontitis: a risk factor for coronary heart disease? Ann Periodontol. 1998;3:127-141.
3. Mattila KJ, Nieminen MS, Valtonen VV, et al. Association between dental health and acute myocardial infarction. BMJ Br Med J (Clin Res Ed). 1989;298(6676):779-781.

4. Mattila KJ, Valle MS, et al. Dental infections and coronary atherosclerosis. Atherosclerosis. 1993;103:205-211.

5. Beck J, Garcia R, et al. Periodontal disease and cardiovascular disease. J Periodontol. 1996:67:1123-1137.

6. Mattila KJ, Valtonen VV, et al. Dental infection and the risk of new coronary events: prospective study of patients with documented coronary artery disease. Clin Infect Dis. 1995;20:588-592.

7. Chauhan $\mathrm{S}$, et al. Prevalence of cardiovascular disease in India and its economic impact- A Review. Int J Sci Res Publ. 2013 Oct;3(10):1-5.

8. Carallo C, Irace C, et al. Evaluation of common carotid hemodynamic forces: relations with wall thickening. Hypertension. 1999;34:217-221.

9. Laurent S, Alivon M, et al. Aortic stiffness as a tissue biomarker for predicting future cardiovascular events in asymptomatic hypertensive subjects. Ann Med. 2012;44:S93-S97.

10. Desvarieux M, et al. Gender differences in the relationship between periodontal disease, tooth loss, and atherosclerosis. Stroke. 2004;35:2029-2035.

11. Linda L. Humphrey et al. Periodontal Disease and Coronary Heart Disease Incidence: a Systematic Review and Meta-analysis. J Gen Intern Med 23; 12:2079-2086.

12. Bahekar A, et al. The prevalence and incidence of coronary heart disease is significantly increased in periodontitis: a meta-analysis. Am Heart J. 2007;154:830-837.

13. Prati $\mathrm{P}$, et al. Carotid IMT and plaques can predict the occurrence of Ischemic Cerebrovascular events. Stroke. 2008;39:2470-2476.

14. Beck JD, Elter JR, Heiss G, et al. Relationship of periodontal disease to carotid artery intima-media wall thickness: the atherosclerosis risk in communities (ARIC) study. Arterioscler Thromb Vasc Biol. 2001;21:1816-1822.

15. Soder PO, Soder B, et al. Early carotid atherosclerosis in subjects with periodontal diseases. Stroke. 2005;36:1195-1200.

16. Carallo C, et al. Common carotid and brachial artery hemodynamic alterations in periodontal disease. J Clin Periodontol. 2013;40:431-436.

17. Amar S, Gokce N, et al. Periodontal disease is associated with brachial artery endothelial dysfunction and systemic inflammation. Arterioscler Thromb Vasc Biol. 2003;23:1245-1249.

18. Holtfreter B, et al. Periodontitis is associated with endothelial dysfunction in a general population: a cross-sectional study. PLoS One. 2013 Dec;8(12):e84603.

19. Krejza J, et al. Carotid artery diameter in men and women and the relation to body and neck size. Stroke. 2006;37:1103-1105

20. Hayashida $\mathrm{H}$, et al. Association of periodontitis with carotid artery intima-media thickness and arterial stiffness in community dwelling people in Japan: the Nagasaki Islands study. Athersclerosis. 2013 Jul;229(1):186-191.

21. Credeur Daniel P, et al. Brachial artery retrograde flow increases with age: relationship to physical function. Eur J Appl Physiol. 2009 Sept;107(2):219-225.

22. van der Heijden-Spek Janneke J, et al. Effect of age on brachial artery wall properties differs from the aorta and is gender dependent a population study. Hypertension. 2000;35:637-642.

23. Beck JD, Elter JR, Heiss G, et al. Relationship of periodontal disease to carotid artery intima-media wall thickness: the atherosclerosis risk in communities (ARIC) study. Arterioscler Thromb Vasc Biol. 2001;21:1816-1822. 